\title{
CrystEngComm
}

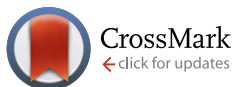

Cite this: CrystEngComm, 2016, 18, 407

Received 24th September 2015, Accepted 27th November 2015

DOI: $10.1039 / c 5 c e 01890 k$

www.rsc.org/crystengcomm

\section{Evaluation of $\mathrm{La}_{1-x} \mathrm{Sr}_{x} \mathrm{MnO}_{3}(0 \leq x<0.4)$ synthesised via a modified sol-gel method as mediators for magnetic fluid hyperthermia $\uparrow$}

\author{
K. McBride, ${ }^{a}$ J. Cook, ${ }^{\text {ab }}$ S. Gray, ${ }^{b}$ S. Felton, ${ }^{b}$ L. Stella ${ }^{a b}$ and D. Poulidi*a
}

A range of lanthanum strontium manganates $\left(\mathrm{La}_{1-x} \mathrm{Sr}_{x} \mathrm{MnO}_{3}-\mathrm{LSMO}\right)$ where $0 \leq x<0.4$ were prepared using a modified peroxide sol-gel synthesis method. The magnetic nanoparticle (MNP) clusters obtained for each of the materials were characterised using scanning electron microscopy (SEM), X-ray powder diffraction (XRD) and infra-red (IR) spectroscopy in order to confirm the crystalline phases, crystallite size and cluster morphology. The magnetic properties of the materials were assessed using the Superconducting quantum interference device (SQUID) to evaluate the magnetic susceptibility, Curie temperature $\left(T_{\mathrm{c}}\right)$ and static hysteretic losses. Induction heating experiments also provided an insight into the magnetocaloric effect for each material. The specific absorption rate (SAR) of the materials was evaluated experimentally and via numerical simulations. The magnetic properties and heating data were linked with the crystalline structure to make predictions with respect to the best LSMO composition for mild hyperthermia $\left(41{ }^{\circ} \mathrm{C} \leq T \leq 46^{\circ} \mathrm{C}\right.$ ). $\mathrm{La}_{0.65} \mathrm{Sr}_{0.35} \mathrm{MnO}_{3}$, with crystallite diameter of $82.4 \mathrm{~nm}$, (agglomerate size of $\sim 10 \mu \mathrm{m}$ ), $T_{\mathrm{C}}$ of $89{ }^{\circ} \mathrm{C}$ and SAR of $56 \mathrm{~W} \mathrm{~g}_{\mathrm{Mn}^{-1}}$ at a concentration $10 \mathrm{mg} \mathrm{mL}^{-1}$ gave the optimal induction heating results $\left(T_{\max }\right.$ of $46.7^{\circ} \mathrm{C}$ ) and was therefore deemed as most suitable for the purposes of mild hyperthermia, vide infra.

\section{Introduction}

Magnetic nanoparticles (MNPs) have emerged as promising mediators for localised magnetic hyperthermia treatment and drug delivery. ${ }^{1}$ The magnetocaloric effect caused by inducing a radio-frequency alternating magnetic field close to an area containing the MNPs leads to a local increase in temperature. When this local increase in temperature occurs within the range of $41-46{ }^{\circ} \mathrm{C}$ it is known as mild hyperthermia. ${ }^{2}$ Mild hyperthermia is a promising therapy at the cellular ${ }^{3}$ and systemic levels, allowing the selective targeting of cancer cells through the exploitation of the characteristic traits of cancer cells whilst minimising the damage to healthy tissue. ${ }^{4-6}$ The therapeutic use of mild hyperthermia is viewed as an adjunct to conventional chemo- or radio- therapies, allowing them to be more effective and require lower dosages as a result. For MNPs to be considered for mild hyperthermia they should be biocompatible; have a low Curie temperature $\left(T_{\mathrm{c}}\right)$, ideally within or close to the therapeutic range of mild hyperthermia (41-46 $\left.{ }^{\circ} \mathrm{C}\right)$; and have a high Specific Absorption Rate (SAR). ${ }^{7}$

\footnotetext{
${ }^{a}$ School of Chemistry and Chemical Engineering, Queen's University Belfast, Stranmillis Road, Belfast BT9 5AG, UK. E-mail: d.poulidi@qub.ac.uk

${ }^{b}$ School of Mathematics and Physics, Queen's University Belfast, University Road, Belfast BT7 1NN, UK

$\dagger$ Electronic supplementary information (ESI) available: Powder X-ray diffraction data, elemental compositions determined by EDX. See DOI: 10.1039/c5ce01890k
}

SAR is a measure of the ability of a material to absorb energy when exposed to electromagnetic radiation.

The vast majority of magnetic nanoparticles investigated for hyperthermia treatment until recently were iron-based ${ }^{8-15}$ which are biocompatible and have high SARs ${ }^{16}$ (of the order of $\left.100 \mathrm{~W} \mathrm{~g}^{-1}\right)$. However, iron-based materials have high $T_{\mathrm{c}} \mathrm{S}$ (ranging from $280{ }^{\circ} \mathrm{C}$ (ref. 17) to $956{ }^{\circ} \mathrm{C}$ (ref. 18)) meaning that application of the magnetic field may lead to overheating of local tissue. ${ }^{19}$ This issue has led to a variety of doped composite materials being developed such as ferrites of $\mathrm{Pd}-\mathrm{Ni}{ }^{7}$ $\mathrm{Ni}-\mathrm{Cu},{ }^{20} \mathrm{Co}-\mathrm{Au}$ (ref. 21) and Co-Zn. ${ }^{22,23}$ The aim of these studies was to reduce the $T_{\mathrm{c}}$ to within the therapeutic range so as to reduce the likelihood of overheating, whilst optimising the SAR. Prior research into perovskite-based manganate MNPs $^{17,24-30}$ also shows them to be promising materials. The potential of these materials as mediators for hyperthermia relies on their perovskite structure. Their composition and as such, magnetic properties, can be tailored without significantly changing the perovskite phase. This can occur by simply distorting the crystal, without compromising the stability. Regardless of the crystal structure the resulting material remains single phase as opposed to composite core-shell materials whose stability may be less predictable. Fig. 1 illustrates the perovskite structure $\mathrm{ABO}_{3}$ present in the manganates. Perovskites have a face-centred cubic lattice with A-sites found on the corners, and the B-sites in the centre of the unit cells. The magnetic properties of a perovskite, 
a)

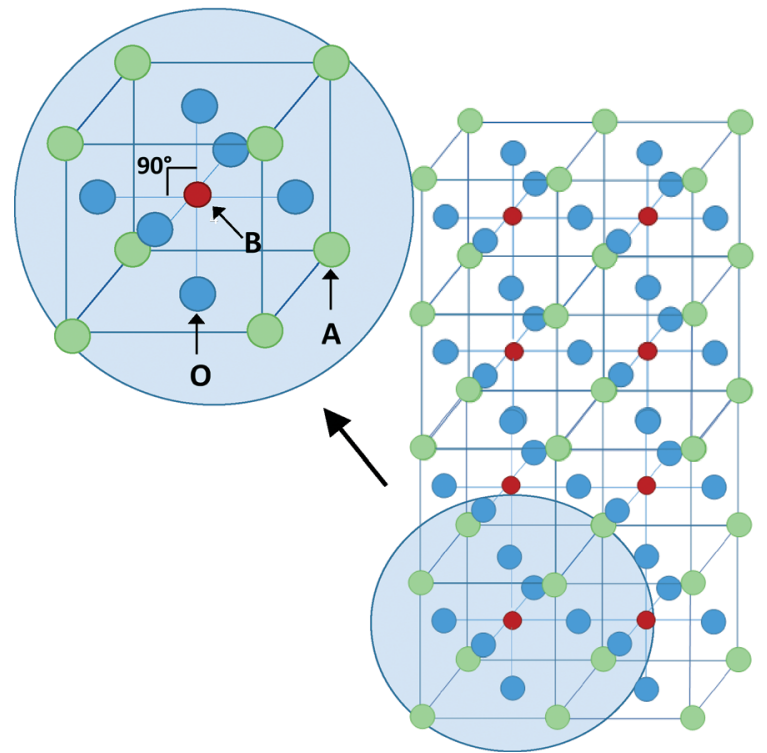

b)

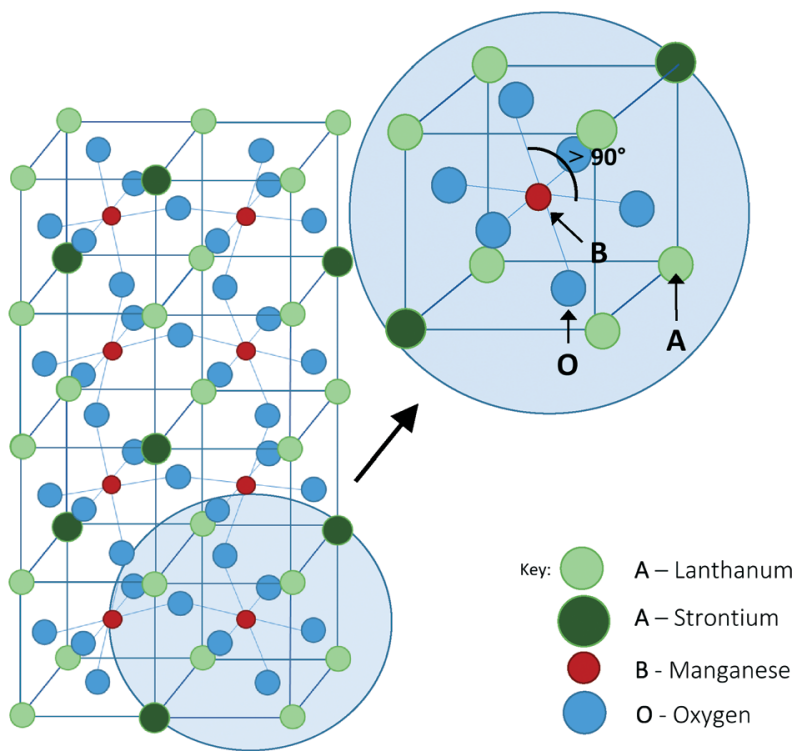

Fig. 1 Structure of perovskites of the type $\mathrm{ABO}_{3}$. Fig. 1a shows the undoped parent compound $\mathrm{LaMnO}_{3}$ and Fig. $1 \mathrm{~b}$ shows the distortion caused to the lattice with dopant in $\mathrm{La}_{1-x} \mathrm{Sr}_{x} \mathrm{MnO}_{3}$ compounds.

including the transition temperature, can be tailored by doping the A and/or B site ions. ${ }^{31,32}$ Altering the magnetic properties of the material may also be achieved by means of altering the method of synthesis. For example, increasing the sintering temperature for $\mathrm{La}_{0.7} \mathrm{Sr}_{0.3} \mathrm{MnO}_{3}$ from $600-1000{ }^{\circ} \mathrm{C}$ leads to an increase in the grain size from 37 to $163 \mathrm{~nm}$ and an increase in $T_{\mathrm{c}}$ from $38-57^{\circ} \mathrm{C} .^{33}$

In this work we have investigated the effect of dopant concentration on the magnetic properties (magnetic susceptibility, SAR and $T_{\mathrm{c}}$ ) of lanthanum strontium manganates $\left(\mathrm{La}_{1-x} \mathrm{Sr}_{x} \mathrm{MnO}_{3}\right)$ prepared using a modified sol-gel method. This perovskite family has been suggested as a candidate material for MNP mediated hyperthermia treatment. ${ }^{6}$ Previous studies have investigated the effect of the particle size ${ }^{33}$ and the effect of altering the composition ${ }^{32,34,35}$ on the magnetic properties of the $\mathrm{La}_{1-x} \mathrm{Sr}_{x} \mathrm{MnO}_{3}$ (LSMO) MNPs. As composition is varied with dopant, a change in magnetic properties is observed. This paper presents a systematic study of the changes in structure, magnetic susceptibility, hysteresis as well as magnetocaloric effect as a result of the changes in composition. The simultaneous investigation of structural changes and changes to physical properties is not usually seen in the literature.

The $\mathrm{La}_{1-x} \mathrm{Sr}_{x} \mathrm{MnO}_{3}$ family is a group of mixed metal oxides of the perovskite structure where $\mathrm{La}^{3+}$ or $\mathrm{Sr}^{2+}$ ions are the A-site cations with either $\mathrm{Mn}^{3+}$ or $\mathrm{Mn}^{4+}$ as the B-site cation. The substitution of $\mathrm{La}^{3+}$ ions for larger $\mathrm{Sr}^{2+}$ ions causes distortion of the local crystal lattice away from the ideal cubic geometry of the parent compound through orthorhombic and rhombohedral structures. This alters the chemical pressure exerted within the lattice, and so alters the bond length of $\mathrm{Mn}-\mathrm{O}$ and the $\mathrm{Mn}^{3+}-\mathrm{O}^{2-}-\mathrm{Mn}^{4+}$ bond angle. Where this bond angle nears $180^{\circ}$ and with decreasing bond length, the extent of $e_{g}$ orbital overlap increases leading to enhancement of the double-exchange mechanism. ${ }^{36}$ The double-exchange mechanism is a type of magnetic exchange whereby an electron is simultaneously transferred from $\mathrm{Mn}^{3+}$ to $\mathrm{O}^{2-}$ while an electron is transferred from $\mathrm{O}^{2-}$ to $\mathrm{Mn}^{4+}$. Enhancement of the double-exchange mechanism leads to enhancement of magnetic properties such as magnetoresistance and the magnetocaloric effect. ${ }^{36}$

The dopant ion may also be used to affect the valency of the B-site cation. For example in $\mathrm{La}_{1-x} \mathrm{Sr}_{x} \mathrm{MnO}_{3}$ with small levels of $\mathrm{Sr}^{2+}$ dopant, the ratio of $\mathrm{La}^{3+}$ to $\mathrm{Sr}^{2+}$ decreases and so the ratio of $\mathrm{Mn}^{4+}$ to $\mathrm{Mn}^{3+}$ increases. Increasing the proportion of $\mathrm{Mn}^{4+}$ towards a 1:1 ratio favours the double exchange mechanism. ${ }^{37} \mathrm{Mn}^{4+}$ is known to be a non Jahn-Teller active ion because its three valence electrons occupy degenerate $t_{2 g}$ orbitals, whereas $\mathrm{Mn}^{3+}$ is Jahn-Teller active due to its four valence electrons in a high spin state occupying nondegenerate orbitals. ${ }^{38}$ This degeneracy causes distortion of the bond lengths in order to minimise the energy of conformation. Therefore, Jahn-Teller distortion will be less effective at increasing the $\mathrm{Mn}^{3+}-\mathrm{O}^{2-}-\mathrm{Mn}^{4+}$ bond angle to $180^{\circ}$ with higher levels of $\mathrm{Sr}^{2+} / \mathrm{Mn}^{4+}$. This would lead to the restriction of the double exchange mechanism, and hence the magnetocaloric effect would be limited. This correlates to the fact that LSMO in the entire range of $0.1<x<0.5$ is in the ferromagnetic phase. ${ }^{37}$

LSMO is being considered here as a mediator for hyperthermia treatment as this family of materials shows the most promise to tune the $T_{\mathrm{c}}$ within the desired range by varying the level of strontium dopant. ${ }^{39}$ In preliminary testing, the maximum $T_{\mathrm{c}}$ recorded for $\mathrm{La}_{0.75} \mathrm{Sr}_{0.25} \mathrm{MnO}_{3}$ was $98{ }^{\circ} \mathrm{C}$ $(60 \mathrm{~nm})^{40}$ compared with $\mathrm{Fe}_{3} \mathrm{O}_{4}$ for which $585{ }^{\circ} \mathrm{C}(100 \mathrm{~nm})$ was observed. ${ }^{26}$ Hence there is more potential to reduce the 
$T_{\mathrm{c}}$ to within therapeutically acceptable levels using manganates by means of altering the preparation method or composition of the material through doping. ${ }^{31,32}$ The method of preparation adopted in this work is a modified peroxide solgel synthesis ${ }^{41}$ which has not been used to synthesise these materials before for the application as mediators for hyperthermia treatment. This facile method of synthesis uses metal oxide and metal carbonate precursors in water, along with hydrogen peroxide and a small amount of ammonium hydroxide. The Pechini ${ }^{42}$ method has been widely used in this area instead as it uses metal nitrate precursors which are extremely soluble and so form a very stable solution. Upon gelation and aging of this solution it is possible to synthesise highly monodisperse and uniform nanoparticles. The modified peroxide sol-gel method was used here as it avoids the use of EDTA and citric acid as the chelating agents, using hydrogen peroxide instead which leads to water as the only by-product of the reaction. It is deemed to be a safer method of preparation in the lab scale as it does not require the use of highly oxidising nitrate precursors. Further investigation in order to achieve better control of the particle size and particle size distribution is currently underway.

\section{Experimental}

\section{Material synthesis}

As mentioned previously an aqueous modified sol-gel method was used in this work based on a method developed by Liu et $a .^{43}$ and Chen et $a .^{44}$ The powder precursors (obtained from Sigma Aldrich); lanthanum(III) oxide, $\geq 99.9 \%$ $\left(\mathrm{La}_{2} \mathrm{O}_{3}\right)$; manganese(II) carbonate, $\geq 99.9 \%$ trace metals basis; and strontium carbonate, $\geq 99.9 \%$ trace metals basis; were added to $150 \mathrm{ml}$ deionised $\mathrm{H}_{2} \mathrm{O}$ in appropriate proportions in order to obtain the desired stoichiometric ratio for the different Sr-doping levels. No thermal pre-treatments were carried out on the powders. While stirring, $100 \mathrm{~mL}$ of hydrogen peroxide (30 vol\% - Fisher Scientific) was added slowly, followed by addition of $3 \mathrm{ml}$ of ammonium hydroxide $\mathrm{NH}_{4} \mathrm{OH}$ (25 vol\%, Sigma Aldrich). Hydrogen peroxide worked as a complexation agent in addition to participating in the oxidation of manganese, while the role of ammonia was to peptize the solution into a stable solution. Chen et al. found that the addition of hydrogen peroxide was necessary in order to obtain a stable solution and xerogel which is why a larger excess of peroxide is used than is needed for simply the oxidation of $\mathrm{Mn}^{2+}$ to $\mathrm{Mn}^{3+}$ and $\mathrm{Mn}^{4+}$. 44

After stirring at $70{ }^{\circ} \mathrm{C}$ for 2 hours, the resulting solution was dried at $90{ }^{\circ} \mathrm{C}$ until dried gel formation. Finally calcination at $1100{ }^{\circ} \mathrm{C}$ for 16 hours was used to remove the residual carbon and obtain a crystalline product. After calcination, the xerogel was converted into a powder which contained the three components in the desired stoichiometric level in the perovskite phase. Table 1 shows all the produced samples and sample names to be used for the remainder of the report. The samples were manually ground before characterisation and testing.
Table 1 Lattice parameters and atomic coordinates for (a) orthorhombic $(P n m a)$ and $(\mathrm{b})$ rhombohedral $(R \overline{3} c)$ which were used to as input parameters for Rietveld analysis

(a) Orthorhombic (Pnma) lattice parameters and atomic coordinates $a=5.5743, b=7.695$ and $c=5.537$

\begin{tabular}{llllc}
\hline Atom & Wycoff position & $x$ & $y$ & $z$ \\
\hline La & $4 \mathrm{c}$ & 0.55 & 0.3 & 0 \\
Mn & $4 \mathrm{a}$ & 0 & 0 & 0 \\
$\mathrm{O}(1)$ & $4 \mathrm{c}$ & -0.011 & 0.3 & -0.1 \\
$\mathrm{O}(2)$ & 8d & 0.309 & 0 & 0.2 \\
\hline
\end{tabular}

(b) Rhombohedral $(R \overline{3} c)$ lattice parameters and atomic coordinates $a=b=5.5212$ and $c=13.37908$

\begin{tabular}{lllll}
\hline Atom & Wycoff position & $x$ & $y$ & $z$ \\
\hline La & $6 \mathrm{a}$ & 0 & 0 & 0.3 \\
Mn & $6 \mathrm{~b}$ & 0 & 0 & 0 \\
O & $18 \mathrm{e}$ & 0.55 & 0 & 0.3
\end{tabular}

\section{Characterisation}

The produced samples underwent a series of analysis in order to obtain the necessary information with respect to the crystalline structure, sample morphology and magnetic properties. Structural determination was carried out using XRD (Panalytical X'Pert) and Fourier Transform Infrared Spectroscopy (FTIR Perkin Elmer Spectrum 2). The Scherrer equation using full-width at half maximum was used to determine the size of the crystallites using the most intense reflection in all cases, which occurred at approximately 32 degrees $2 \theta$. As the Bragg angle is obtained to 4 decimal places, the error propagation of the trigonometric Scherrer function comes to a value of $\pm 0.1 \mathrm{~nm}$ in keeping with the values quoted. X'Pert High Score Plus was used to carry out a Rietveld analysis on the diffraction patterns of the crystalline phases present in the powder samples. The input lattice parameters and atomic coordinates which best matched the experimental data are shown in Table 1a and b. The background was not subtracted and refinement of the atomic coordinates of both phases was undertaken before refining the instrumental parameters. The morphology of the resulting samples was studied using SEM (eSEM - FEI Quanta FEG - Environmental SEM Oxford ExACT). The concentration of dopants in the synthesised materials was then confirmed using eSEM-EDX with the Aztec based XACT system. Atomic percentage was determined using the relative ratio of $\mathrm{La}$ to $\mathrm{Sr}$ elements in each sample. A cobalt standard was used with the uncertainty for the data values at the $\pm 1 \%$ level. The magnetic susceptibility and magnetisation hysteresis were measured using a superconducting quantum interference device (SQUID) magnetometer (Quantum Design MPMS XL). Field dependent magnetisation measurements were conducted in the range $-10000 \leq H \leq 10000 \mathrm{Oe}$, at $100 \mathrm{~K}$ and $200 \mathrm{~K}$. Susceptibility measurements were conducted in field cooled (FC) and zero field cooled (ZFC) conditions between 100 and $370 \mathrm{~K}$, at 500 Oe. Non-adiabatic heating experiments were conducted using an RF magnetic field generator (Easyheat 0112) coupled with a water-cooled induction coil (6-turn $12 \mathrm{~cm}$ length coil). 
A schematic of the induction rig used for the magnetic heating measurements is shown in Fig. 2. The generated magnetic field characteristics were frequency: $175 \mathrm{kHz}$ and amplitude: $10.95 \mathrm{kAm}^{-1}$. Aqueous suspensions of the MNPs of concentrations 5,10 and $15 \mathrm{mg} \mathrm{mL}^{-1}$ were prepared. The temperature of the aqueous suspension during the induction heating experiments was measured with an IR temperature probe (Optocon AG) FOTEMP 1 coupled to a (Optocon AG) TS2/2 sensor. The heating curves from the induction heating experiments are presented in terms of temperature difference rather than measured temperature to reduce systematic errors. The results obtained from the induction heating measurements were used to calculate the SAR. The corrected slope method was used here to ensure reliable results which can be compared between different experimental set-ups. The SAR was estimated using the following equation: ${ }^{45}$

$$
\mathrm{SAR}_{\text {corrected slope }}=\frac{C_{\mathrm{w}} \frac{\Delta T_{\mathrm{w}}}{\Delta t}+L \Delta T_{\mathrm{w}}}{m_{\mathrm{MNP}}}
$$

where $C_{\mathrm{w}}$ is the specific heat capacity $\left(\mathrm{J} \mathrm{g}^{-1} \mathrm{~K}^{-1}\right)$ of water, $m_{\mathrm{MNP}}$ is the weight fraction of the magnetically active element, $\Delta T_{\mathrm{w}} / \Delta t$ is the change in temperature against time, and $L$ is the thermal losses of the system (taken from the literature ${ }^{45}$ ).

It has been recently reported that a temperature increase ( $3{ }^{\circ} \mathrm{C}$ in a 10 minute period) may be observed without a magnetic sample present inside the induction coil. This is a result of large currents flowing through the induction coil causing additional convectional heating. ${ }^{45}$ As a result, the temperature of $1 \mathrm{~mL}$ of water was also measured under the same conditions to act as a blank experiment in order to correctly attribute heating effects as being due to the magnetocaloric effect of the material. We found that for our experimental settings, the temperature of the blank reproducibly increased by $3{ }^{\circ} \mathrm{C}$ in a 10 minute period when the initial temperature was $25{ }^{\circ} \mathrm{C}$, in agreement with the literature. The magnetic heating curves here are not scaled to remove the blank heating profile as they would then not be comparable to other published results. However, the blank is taken into consideration when calculating the linear loss parameter for the SAR using Wildeboer et al.'s method. ${ }^{45}$ We use the SAR of

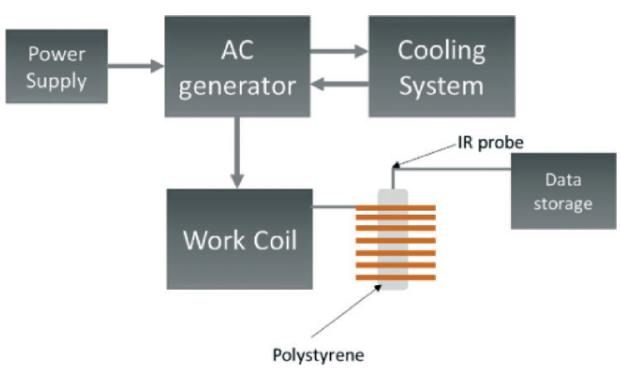

Fig. 2 Schematic of equipment used for the induction heating experiments. the blank in Fig. 8 and 9 as a guide to compare SARs for the range of materials.

The experimental heating curves were modelled using a simple two-temperature model. ${ }^{46}$ This model is based on the balance between: (i) the energy absorbed by the MNP; (ii) the energy released by the MNP to the solvent; (iii) the heat loss to the environment. This energy balance can be written down as a system of two ordinary differential equations:

$$
\left\{\begin{array}{l}
f_{\mathrm{m}} C_{\mathrm{p}}^{(\mathrm{m})} \frac{\mathrm{d} T_{\mathrm{m}}}{\mathrm{d} t}=f_{\mathrm{m}} K_{\mathrm{rf}}-f_{\mathrm{m}} g\left(T_{\mathrm{m}}-T_{\mathrm{s}}\right), \\
C_{\mathrm{p}}^{(\mathrm{s})} \frac{\mathrm{d} T_{\mathrm{s}}}{\mathrm{d} t} f_{\mathrm{m}} g\left(T_{\mathrm{m}}-T_{\mathrm{s}}\right)-K_{\text {out }}\left(T_{\mathrm{s}}-T_{\text {room }}\right),
\end{array}\right.
$$

where $T_{\mathrm{m}}$ is the temperature of the MNP, $T_{\mathrm{s}}$ is the temperature of the solvent, $T_{\text {room }}$ is the temperature of the environment, $C_{\mathrm{p}}^{(\mathrm{m})}$ is the specific heat capacity at constant pressure of the MNP,$C_{\mathrm{p}}^{(\mathrm{s})}$ is the specific heat capacity at constant pressure of the solvent, $f_{\mathrm{m}}$ is the sample concentration of MNPs in water, $g$ is specific heat transfer coefficient, $K_{\mathrm{rf}}$ is the specific absorption rate of the MNPs (and not per $g_{M n}$ as is the SAR), and $K_{\text {out }}$ is the specific loss rate of the solvent to the environment. To simplify the calculations, we assume that all the parameters in the equations are temperature independent. In particular, we set $C_{\mathrm{p}}^{(\mathrm{m})}=1.44706 \times 10^{3} \mathrm{~J} \mathrm{~kg}^{-1} \mathrm{~K}^{-1}$ and $C_{\mathrm{p}}^{(\mathrm{s})}=42 \times 10^{3} \mathrm{~J} \mathrm{~kg}^{-1} \mathrm{~K}^{-1}$ (for water). The sample concentration has been set to $f=10 \mathrm{mg} \mathrm{g}^{-1}=0.01$.

\section{Results and discussion}

\section{Crystalline structure and configuration analysis}

Table 2 shows the stoichiometry of the synthesised samples as verified by EDX to be in keeping with the desired ratios (the EDX maps of all samples are provided in the ESI $\dagger$ ). In Fig. 3 the XRD patterns for the LSMO samples can be seen. An increasing proportion of the secondary phase of $\mathrm{SrMnO}_{3}$ is visible with increasing strontium dopant. Also evident is the increasing intensity of the reflections and (110) in particular, with increasing strontium dopant. Peaks at $28-30^{\circ} 2 \theta$ are likely to be due to contamination with agate during manual grinding. Other potential secondary phases which may be present in even smaller amounts include $\mathrm{La}_{2} \mathrm{O}_{3}, \mathrm{MnCO}_{3}$ and $\mathrm{SrMnO}_{3} \cdot{ }^{47}$ Previous observations by Zhang et al. have shown that for $x<0.2$ the orthorhombic geometry is typically dominant, followed by a transition to rhombohedral geometry for $0.25<x<0.5$. ${ }^{48}$ On initial assessment of the diffraction patterns our data seemed to support this but the presence of more than one phase is evident in the shallow transition in magnetic susceptibility vide infra. On completion of Rietveld analysis of the samples we found that all samples produced via this modified peroxide sol-gel method contained mixed crystalline phases. The calculated crystalline phases which best fitted the experimental data were found to be orthorhombic $(P n m a)^{49}$ and rhombohedral $(R \overline{3} c)^{50}$ crystal structures. The rhombohedral $(R \overline{3} c)$ geometry appears to be the dominant crystalline phase for all the samples presented here 
(a)

(b)
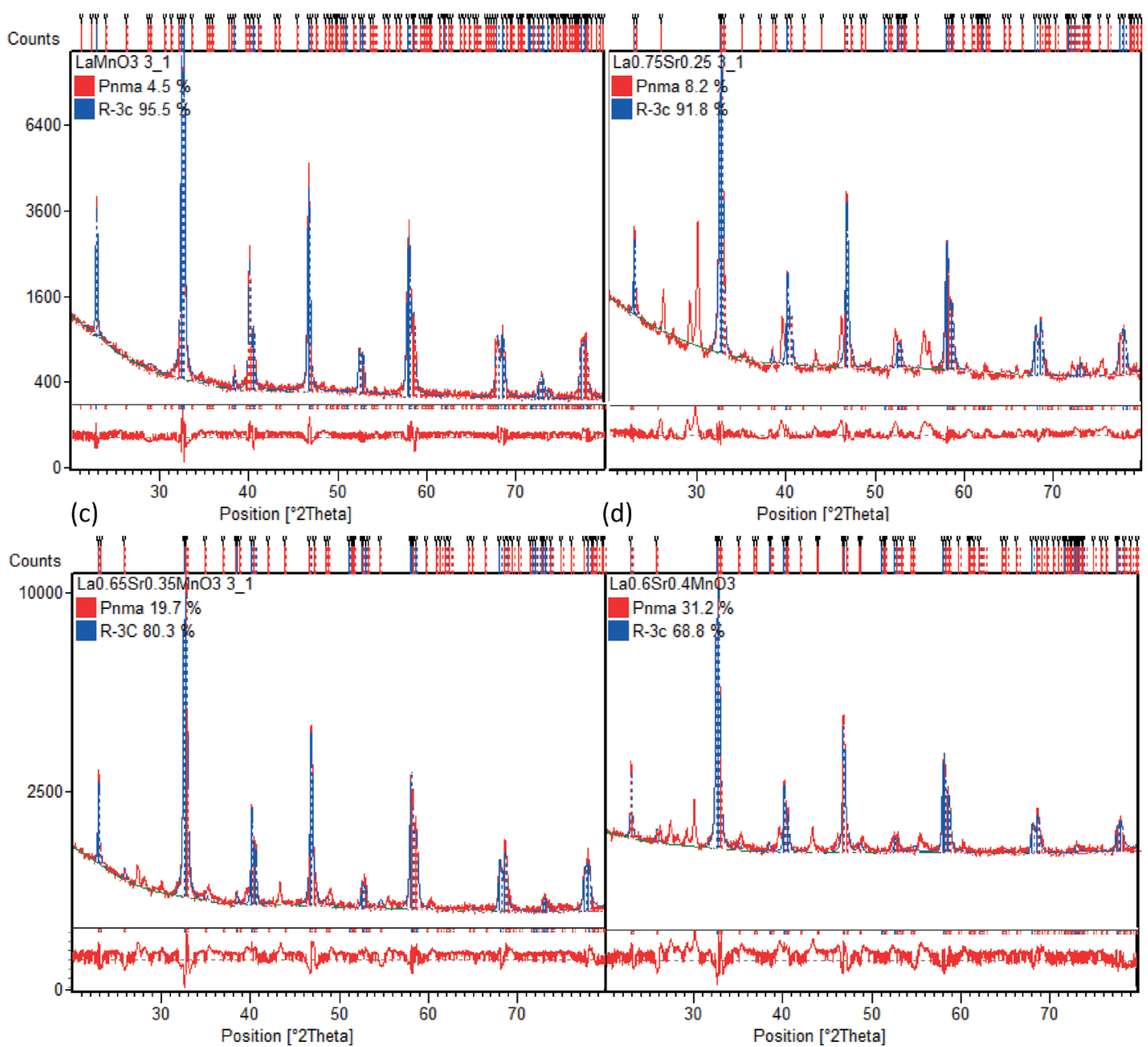

Fig. 3 Rietveld analyses of X-ray diffraction patterns of a selection of LSMO materials (a) LMO (b) LSMO25 (c) LSMO35 and (d) LSMO40 to quantify the relative weight percentages of orthorhombic (Pnma) and rhombohedral $(R \overline{3} c)$ crystalline phases. The red line below each diffraction pattern is the difference plot which gives an indication of the variation between the calculated and experimental data.

(LMO, LSMO25, LSMO35 and LSMO40) in keeping with literature. ${ }^{51-53}$ Fig. 4 shows that with increasing strontium
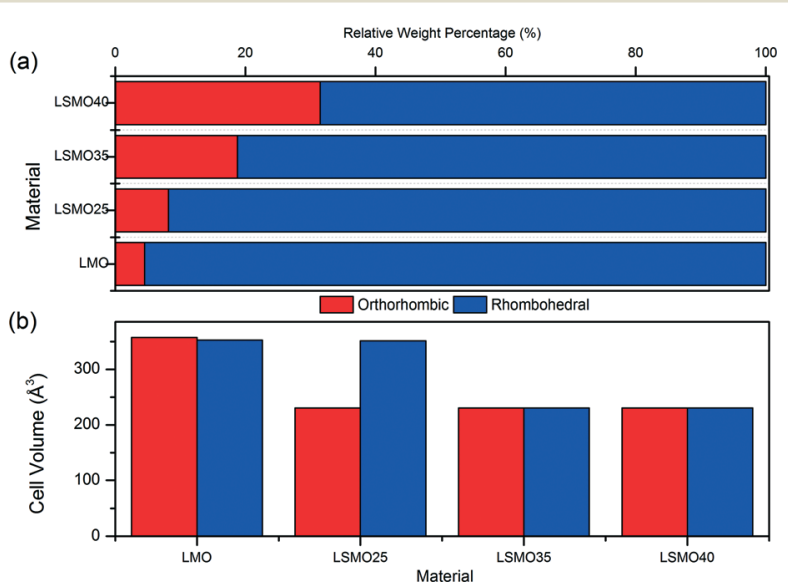

Fig. 4 Crystal structure comparison of orthorhombic and rhombohedral phases for (a) relative weight percentages and (b) unit cell volumes for LMO, LSMO25, LSMO35 and LSMO40. dopant, the relative weight percentage of the orthorhombic (Pnma) crystalline phase increases. This is in keeping with Dokiya et al. who documented the structural transition of

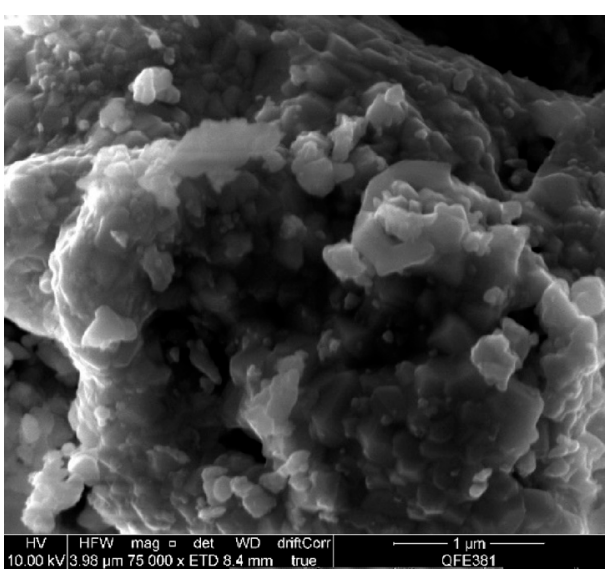

Fig. 5 Scanning electron micrograph of LSMO40. 


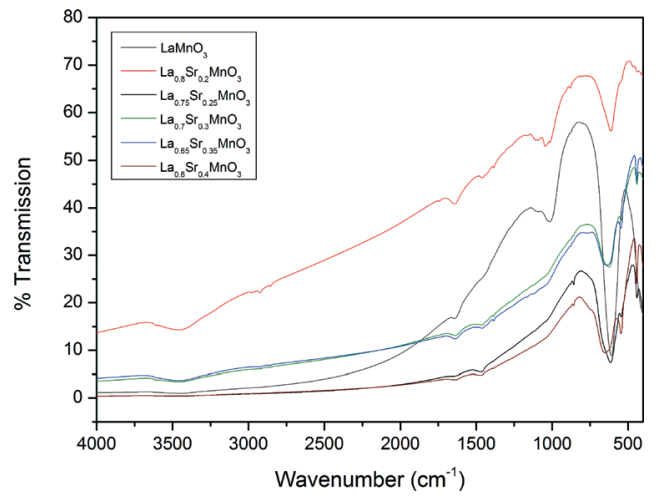

Fig. 6 IR spectra for a range of the doped LSMO materials where $x=$ 0.2 to 0.4 compared to the parent compound $\mathrm{LaMnO}_{3}$.

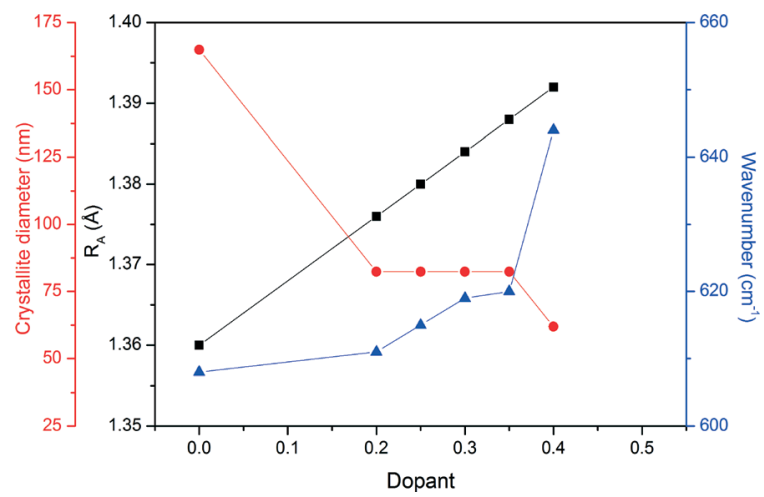

Fig. 7 The relationship between the average radii of A-site cations $\left(R_{A}\right)$, crystallite diameter and wavenumber for the range of doped LSMO materials. Black squares correspond to $R_{A}$, red circles to the crystallite diameter, and blue triangles to the $\mathrm{Mn}-\mathrm{O}$ wavenumber. Connecting lines are included as a guide to the eye.

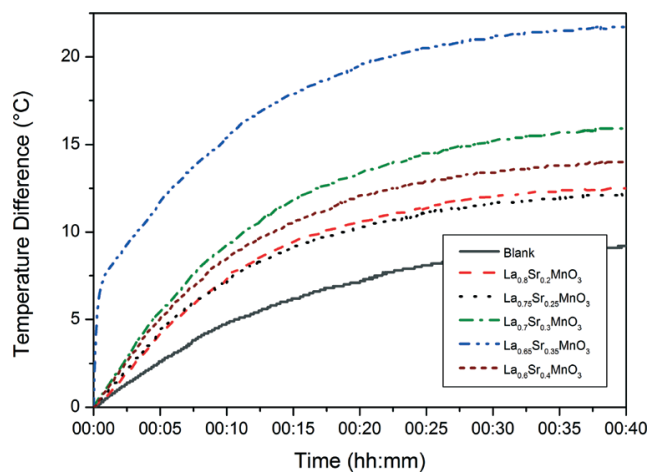

Fig. 8 Heating curves of the range of doped LSMO materials using aqueous suspension of $10 \mathrm{mg} \mathrm{mL}^{-1}$.

LSMO from rhombohedral $(R \overline{3} c)$ to higher orthorhombic and rhombohedral symmetries with increasing strontium dopant or decreasing oxygen content. ${ }^{49}$

Table 3 shows the calculated structural information for the LSMO samples. We can see that the A-site substitution of lanthanum with cationic radius of $1.36 \AA$ for strontium with

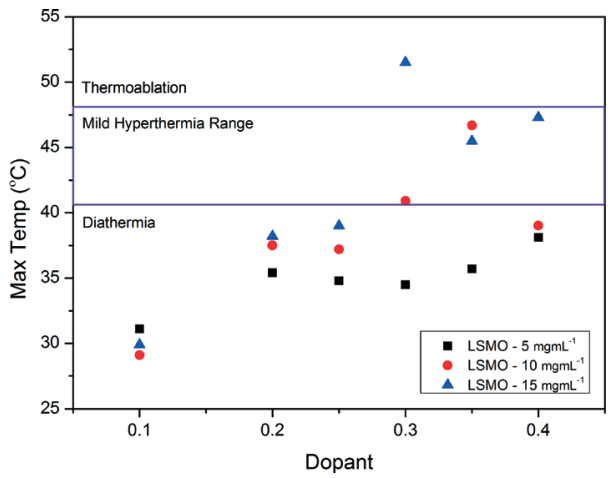

Fig. 9 Maximum temperatures reached by the range of doped LSMO materials at various suspension concentrations.

a larger cationic radius of $1.44 \AA$ does not account for the decrease in cell volume with increasing dopant concentration for both phases. The decrease in cell volume is therefore ascribed to the decreasing ionic radii of the B-site with increasing strontium dopant, which causes $\mathrm{Mn}^{3+}$ with cationic radii of $0.645 \AA$ to be replaced by the smaller $\mathrm{Mn}^{4+}$ with cationic radii of $0.53 \AA{ }^{54}$ There appears to be little difference in cell volumes for orthorhombic and rhombohedral crystalline phases in each of the LMO, LSMO35 and LSMO40 samples. For LSMO25 however, the cell volume of the rhombohedral structure is $52 \%$ greater than for the orthorhombic structure. It is at this point that the relative weight percentage of the rhombohedral phase begins to more rapidly decline, with the orthorhombic phase more rapidly increasing. For both crystal phases we can see a reduction in cell volume of approximately $35 \%$ between $x=0$ and $x=0.35$. It is in this range that we could expect the material to have enhanced magnetic properties as the decrease in cell volume would lead to shorter bond lengths with greater bonding orbital overlap meaning the double exchange mechanism will be more effective. The change in crystal structure from rhombohedral to orthorhombic geometry also means that $\gamma$ has decreased from $120-90^{\circ}$. In doing so this should mean that a greater proportion of $\mathrm{Mn}^{3+}-\mathrm{O}-\mathrm{Mn}^{4+}$ bonds are close to $180^{\circ}$ for optimal double exchange. ${ }^{36}$ By this rationale LSMO35 and LSMO40 should be able to participate more effectively in the double exchange mechanism and therefore exhibit better magnetocaloric effect. The SEM analysis shown in Fig. 5 (LSMO40) indicates that the samples consist of agglomerates of nanoparticles of the order of $10 \mu \mathrm{m}$.

Fig. 6 shows the FTIR analysis results for the prepared LSMO samples. The presence of octahedral $\mathrm{MnO}_{6}$ due to the absorption at approximately $600 \mathrm{~cm}^{-1}$ by the $\mathrm{Mn}-\mathrm{O}$ bond can be seen in all cases. However, there is a positive shift in the wavenumber of this absorption with increasing dopant concentration. Fig. 7 depicts the calculated parameters from the XRD and FTIR analysis (crystallite size, average A-site cation radius and $\mathrm{Mn}-\mathrm{O}$ bond absorption wavenumber) as a function of the dopant concentration. We can see that increasing the dopant concentration (and as a result the average radius of the A-site cation) decreases the crystallite diameter for 
Table 2 Key characterisations on samples presented in this work including the stoichiometry of each sample as determined by EDX analysis, as well as the average crystallite diameter calculating using the Scherrer equation using the most intense peak

\begin{tabular}{llllllllll}
\hline Sample & $\begin{array}{l}\text { Sample } \\
\text { name }\end{array}$ & EDX & XRD & IR & $\begin{array}{l}\text { Induction } \\
\text { heating }\end{array}$ & SEM & $\begin{array}{l}M v s . T \\
\text { (SQUID) }\end{array}$ & $\begin{array}{l}\text { M V H } \\
\text { (SQUID) }\end{array}$ & $\begin{array}{l}\text { EDX } \\
\text { stoichiometry }\end{array}$ \\
\hline $\mathrm{LaMnO}_{3}$ & LMO & & $\checkmark$ & $\checkmark$ & $\checkmark$ & & & - \\
(nm)
\end{tabular}

Table 3 Refined lattice parameters resulting from Rietveld analysis for LMO, LSMO25, LSMO35 and LSMO40 (Gof - goodness of fit)

\begin{tabular}{|c|c|c|c|c|c|c|c|c|c|c|c|c|c|c|}
\hline LMO & Rhombohedral & 5.52248 & 5.5225 & 13.3686 & 90 & 90 & 120 & 353.1 & $R \overline{3} c$ & & & 6.2 & & 95.5 \\
\hline & Rhombohedral & 5.51461 & 5.5146 & 13.3552 & 90 & 90 & 120 & 351.7 & $R \overline{3} c$ & & & 2.64 & & 91.8 \\
\hline \multirow{2}{*}{ LSMO35 } & Orthorhombic & 5.44815 & 7.7433 & 5.46776 & 90 & 90 & 90 & 230.4 & Pnma & 8.2 & 3.8 & 18.8 & 4.6 & 19.7 \\
\hline & Rhombohedral & 5.51197 & 5.5119 & 13.3546 & 90 & 90 & 120 & 351.4 & $R \overline{3} c$ & & & 28.8 & & 80.3 \\
\hline
\end{tabular}

LSMO and in turn shortens the bond angle $\beta$ (shown in Table 3) until a geometrical transition (from rhombohedral to orthorhombic) is observed while increasing the Mn-O wavenumber. This increase in wavenumber is evidence of the increasing energy required to manipulate the $\mathrm{Mn}-\mathrm{O}$ bond in the more distorted octahedron where the geometric transition has occurred to reduce strain. For LSMO samples where $0.2<x<0.35$ the crystallite diameter remains constant, yet increasing strain caused by increasing dopant concentration creates greater internal pressure in the perovskite lattice. This internal pressure, based on this rationale is at its maximum for LSMO35, where we begin to see a significant change in the relative weight percentages of the orthorhombic and rhombohedral geometries. As it is in a region of magnetic phase transition in which the optimal magnetocaloric effect may be observed, we may expect the maximum caloric effect for the LSMO35 sample. This hypothesis will be evaluated next when the magnetisation and induction heating experiments are discussed.

\section{Magnetic heating experiments}

Fig. 8 shows the heating curves for doped LSMO samples where $0.2<x<0.35$ for sample concentration of $10 \mathrm{mg} \mathrm{mL}^{-1}$; we can see that as dopant increases so does the maximum temperature reached by each heating profile until an optimum is reached, after which this maximum temperature of saturation decreases again. Fig. 9 shows the saturation temperature achieved for all LSMO samples at the three different concentrations ( $5 \mathrm{mg} \mathrm{mL}^{-1}, 10 \mathrm{mg} \mathrm{mL}^{-1}$ or $15 \mathrm{mg} \mathrm{mL}^{-1}$ ); in general increasing the suspension concentration increases the maximum temperature achieved. For example; where $x=0.3$, the maximum temperature reached increases from $34.5{ }^{\circ} \mathrm{C}$ at $5 \mathrm{mg} \mathrm{mL}{ }^{-1}$, to $40.9{ }^{\circ} \mathrm{C}$ at $10 \mathrm{mg} \mathrm{mL}^{-1}$, and to $51.5{ }^{\circ} \mathrm{C}$ at
$15 \mathrm{mg} \mathrm{mL}$. The dopant concentration for obtaining the optimal maximum temperature is also a function of the suspension concentration dropping from $x=0.4$ for $5 \mathrm{mg} \mathrm{mL}^{-1}$ $\left(38.1{ }^{\circ} \mathrm{C}\right)$ to $x=0.35$ for $10 \mathrm{mg} \mathrm{mL}^{-1}\left(46.7^{\circ} \mathrm{C}\right)$ and to 0.3 for $15 \mathrm{mg} \mathrm{mL}{ }^{-1}\left(51.5{ }^{\circ} \mathrm{C}\right)$. The temperatures of both the blank sample and the parent compound $\mathrm{LaMnO}_{3}$ increase with time in the AC field by similar amounts. In Fig. 10 we can see that the optimal SARs at concentrations of 5, 10 and $15 \mathrm{mg} \mathrm{mL}^{-1}$ are found for samples where $0.3<x<$ 0.35 . SARs are higher for the range of doped samples when tested at lower concentrations. As SAR is calculated per gram of the magnetic material, the observed decrease in SAR is expected with increasing sample concentration. The greatest optimal SAR of $59.43 \mathrm{~W} \mathrm{~g}_{\mathrm{Mn}}{ }^{-1}$ was obtained at a concentration of $5 \mathrm{mg} \mathrm{mL}^{-1}$ where $x=0.35$. However the maximum temperature achieved by this sample concentration was $35.7^{\circ} \mathrm{C}$. Eqn (2) and (3) have also been solved numerically and the result for $T_{\mathrm{s}}(t)$ has been fitted to the experimental heating

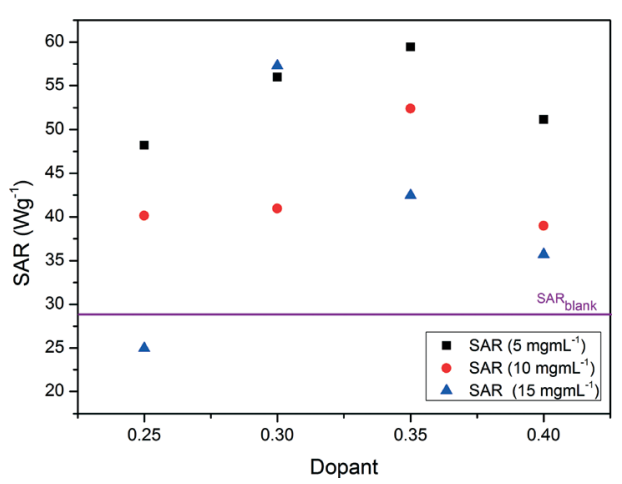

Fig. 10 Specific absorption rates reached by the range of doped LSMO materials. 
values using a standard least squares regression. The calculated parameters (as discussed previously) as a function of the doping, $x$, are shown in Table 4 . These are in very good agreement with the SARs calculated using Wildeboer et al.'s $\operatorname{method}^{45}$ shown in Fig. 10.

For the efficacy of the hyperthermia treatment as previously stated, the heat generated should be within the mild hyperthermia range of $41-46^{\circ} \mathrm{C}$ with a high SAR. Based on these two considerations, further work was done using LSMO where $x=0.35$ and a suspension concentration of $10 \mathrm{mg}$ $\mathrm{mL}^{-1}$ in order to achieve a maximum temperature of $46.7^{\circ} \mathrm{C}$ at $10 \mathrm{mg} \mathrm{mL}^{-1}$.

\section{Magnetic measurements}

Fig. 11 shows the magnetic susceptibility of the materials with respect to temperature. All samples show a ferromagnetic to paramagnetic transition where the zero-field cooled and field cooled curves overlap. The susceptibilities of the LSMO materials in Fig. 11 decrease with increasing dopant from $x=0.25$ to $x=0.4$. These LSMO materials have a shallow transition region, exhibiting multiplicity as two slight inflections are observed on each graph. This indicates that the LSMO samples contain more than one magnetic phase present. Comparing the susceptibility measurements with the magnetic heating results we can see that the materials with lower susceptibilities produce a greater magnetocaloric effect and vice versa. We would expect to see that since, as the susceptibility of the material decreases, the A.C. hysteretic loss contributions in particular would increase (vide infra).

Table 5 shows the corresponding $T_{\mathrm{c}} \mathrm{s}$ which were calculated from the susceptibility measurements. The $T_{\mathrm{c}}$ was

Table 4 Calculated modelling parameters

\begin{tabular}{llllll}
\hline$x$ & $K_{\mathrm{rf}} \mathrm{W} \mathrm{kg}^{-1}$ & $\mathrm{~g} \mathrm{~W} \mathrm{~kg}^{-1} \mathrm{~K}^{-1}$ & $K_{\text {out }} \mathrm{W} \mathrm{kg}^{-1} \mathrm{~K}^{-1}$ & $\mathrm{SAR} \mathrm{W} \mathrm{g}_{\mathrm{Mn}}{ }^{-1}$ & $T_{\max }\left({ }^{\circ} \mathrm{C}\right)$ \\
\hline 0.20 & 12733 & 56.66 & 6.006 & 53.67 & 35.60 \\
0.25 & 11507 & 50.60 & 5.684 & 47.97 & 35.12 \\
0.30 & 12888 & 124.01 & 6.706 & 53.12 & 34.61 \\
0.40 & 13210 & 104.65 & 6.052 & 53.83 & 35.91
\end{tabular}

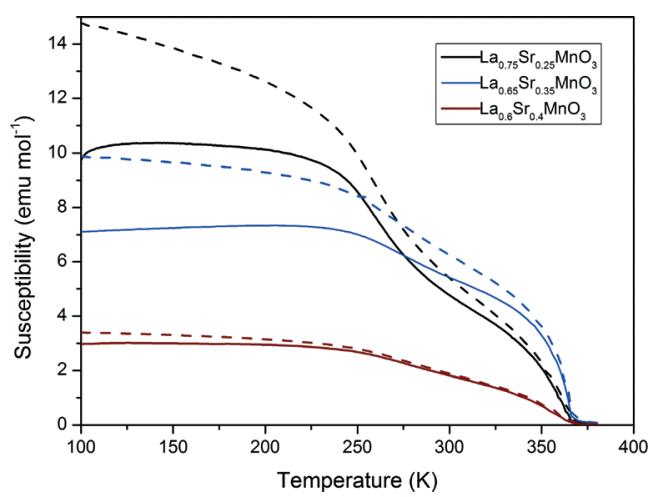

Fig. 11 Magnetic susceptibly measurements for a selection of LSMO samples (dashed lines represent ZFC and full lines FC measurements).
Table 5 Parametric characterisation of hysteresis for a selection of doped LSMO materials $\left(M_{\mathrm{s}}\right.$ - saturation magnetisation, $H_{\mathrm{c}}$ - coercivity, $B_{\mathrm{r}}$ - remanence, $W$ - hysteretic losses and $T_{\mathrm{c}}$ - Curie temperature)

\begin{tabular}{|c|c|c|c|c|c|c|}
\hline Sample & $\begin{array}{l}M_{\mathrm{s}} \\
\text { emu } \mathrm{mol}^{-1}\end{array}$ & $H_{\mathrm{c}} \mathrm{Oe}$ & $\begin{array}{l}B_{\mathrm{r}} \\
\text { emu } \mathrm{mol}^{-1}\end{array}$ & $\begin{array}{l}W_{100 \mathrm{k}} \\
\mathrm{J} \mathrm{g}_{\mathrm{Mn}}{ }^{-1}\end{array}$ & $\begin{array}{l}W_{150 \mathrm{k}} \\
\mathrm{J} \mathrm{g}_{\mathrm{Mn}}{ }^{-1}\end{array}$ & $T_{\mathrm{c}} \mathrm{K}$ \\
\hline LSMO25 & 12800 & 25 & 339 & 5400 & 15900 & 346 \\
\hline LSMO35 & 13000 & 75 & 408 & 4300 & 11400 & 362 \\
\hline LSMO40 & 3500 & 50 & 155 & 1600 & 1000 & 352 \\
\hline
\end{tabular}

estimated for each sample using the Arrott plot method. Increasing from $x=0.25$ to 0.35 for LSMO, we see that $T_{\mathrm{c}}$ increases and then decreases again where $x=0.40$. The sample where $x=0.4$ has a higher $T_{\mathrm{c}}$ than the phase diagram would suggest. ${ }^{37}$ However all calculated $T_{\mathrm{c}} \mathrm{s}$ are in keeping with experimental trends reported by Urushibara et al. ${ }^{40}$

Fig. 12 shows the hysteresis loops recorded for each of the materials for $x=0.25,0.35$ and 0.4 at $100 \mathrm{~K}$ between -5000 and 5000 Oe. The calculated areas of hysteresis are listed in Table 5. These values show a similar trend to that of the susceptibility measurements. Hysteretic losses decrease with increasing dopant from $x=0.25$ to $x=0.4$. The decrease in hysteretic losses with increasing dopant can be attributed to the increasing substitution of Jahn-Teller active $\mathrm{Mn}^{3+}$ for non Jahn-Teller active $\mathrm{Mn}^{4+}$. The decrease in Jahn-Teller

(a)

(b)
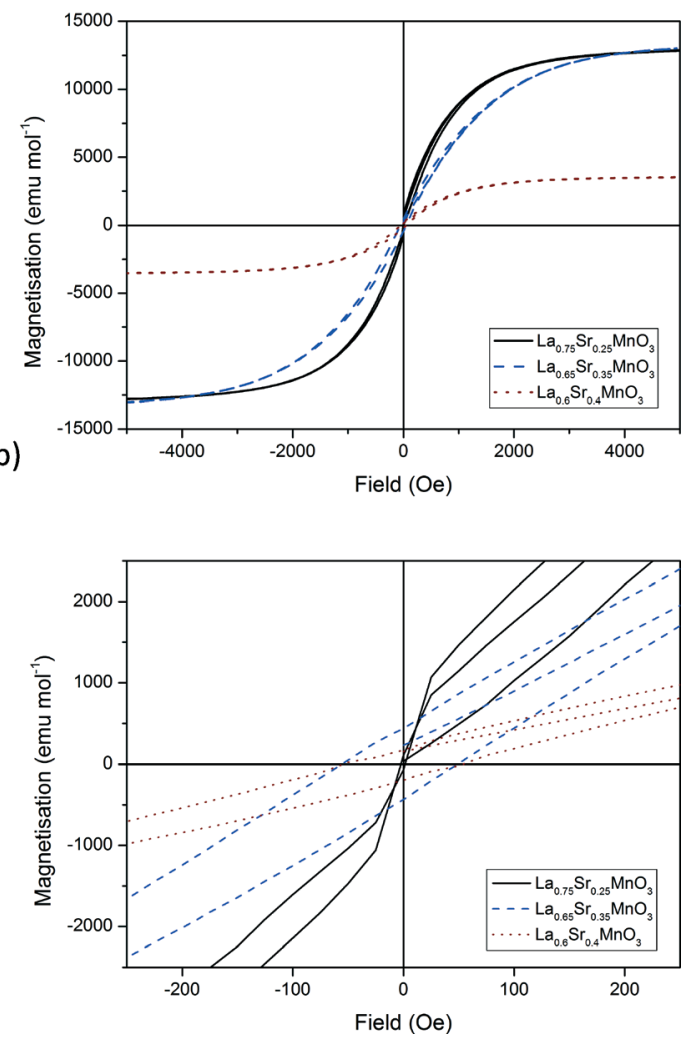

Fig. 12 Hysteresis loops for a selection of doped LSMO materials at 100 K. (a) Complete field range (-5000 to 5000 Oe) and (b) zoom in from -250 to +250 Oe. 
active ions causes a decrease in the extent of the double exchange mechanism and magnetocaloric effect vide priori. Increasing the temperature from 100-150 K increases the hysteretic losses three-fold for LSMO25 and LSMO35. However no significant increase in hysteretic losses is calculated for LSMO40.

An inverse trend is observed for LSMO with respect to hysteretic losses and magnetocaloric effect. It must be stressed however that the two types of measurements (i.e. induction heating and static hysteretic losses) are not directly comparable so no further conclusions can be drawn at this stage.

\section{Conclusions}

The polycrystalline structure of a family $\mathrm{La}_{1-x} \mathrm{Sr}_{x} \mathrm{MnO}_{3}$ of perovskite-type MNP clusters with different dopant concentrations was evaluated and linked with the magnetic properties of the materials with the aim to make predictions with respect to the best LSMO composition for use as a mild hyperthermia mediator. Taking into consideration the target temperature range and requirement for a low MNP dosage for therapeutic application, whilst maintaining a high SAR it was found that $\mathrm{La}_{0.65} \mathrm{Sr}_{0.35} \mathrm{MnO}_{3}$ appeared be the most suitable material. It was found that a transition in the crystalline structure of the perovskite crystal between rhombohedral and orthorhombic increases the magnetocaloric properties of LSMO. FTIR has been shown to be a useful technique in order to compare potential mediators and to predict their magnetocaloric properties. This study presents the magnetic properties (magnetic susceptibility, hysteretic and heating experiment measurements) of the overall sample containing the agglomerated nanoparticles, not the nanoparticles themselves. As we are looking at the magnetic properties of the overall sample as a result of changing the dopant, a TEM study on the nanoparticles would be beyond the scope of this project. Further detailed studies on the stoichiometry of the crystalline phases for the actual magnetic nanoparticles are however planned for future work.

\section{Acknowledgements}

Katherine McBride and Suzanne Gray would like to acknowledge financial support from the Department of Education and Learning Northern Ireland (DEL-NI) for a PhD studentship. The authors also acknowledge the help of Professor David Rooney and Christopher McCallum for their help with the induction heating experiments.

\section{Notes and references}

1 Y. Fukumori and H. Ichikawa, Adv. Powder Technol., 2006, 17, 1-28.

2 A. Jordan, R. Scholz, P. Wust, H. Fähling and R. Felix, J. Magn. Magn. Mater., 1999, 201, 413-419.

3 L. Asín, M. R. Ibarra, A. Tres and G. F. Goya, Pharm. Res., 2012, 29, 1319-1327, DOI: 10.1007/s11095-012-0710-z.
4 K. Maier-Hauff, F. Ulrich, D. Nestler, H. Niehoff, P. Wust, B. Thiesen, H. Orawa, V. Budach and A. Jordan, J. Neuro-Oncol., 2011, 103, 317-324, DOI: 10.1007/s11060-010-0389-0.

5 F. K. H. van Landeghem, K. Maier-Hauff, A. Jordan, K. Hoffmann, U. Gneveckow, R. Scholz, B. Thiesen, W. Brück and A. von Deimling, Biomaterials, 2009, 30, 52-57.

6 A. Jordan, R. Scholz, P. Wust, H. Schirra, T. Schiestel, H. Schmidt and R. Felix, J. Magn. Magn. Mater., 1999, 194, 185-196.

7 O. A. Kuznetsov, O. N. Sorokina, V. G. Leontiev, O. A. Shlyakhtin, A. L. Kovarski and A. A. Kuznetsov, J. Magn. Magn. Mater., 2007, 311, 204-207.

8 N. A. Brusentsov, V. V. Gogosov, T. N. Brusentsova, A. V. Sergeev, N. Y. Jurchenko, A. A. Kuznetsov, O. A. Kuznetsov and L. I. Shumakov, J. Magn. Magn. Mater., 2001, 225, 113-117.

9 N. A. Brusentsov, T. N. Brusentsova, E. Y. Filinova, N. Y. Jurchenko, D. A. Kupriyanov, Y. A. Pirogov, A. I. Dubina, M. N. Shumskikh, L. I. Shumakov, E. N. Anashkina, A. A. Shevelev and A. A. Uchevatkin, J. Magn. Magn. Mater., 2007, 311, 176-180.

10 R. Di Corato, A. Espinosa, L. Lartigue, M. Tharaud, S. Chat, T. Pellegrino, C. Ménager, F. Gazeau and C. Wilhelm, Biomaterials, 2014, 35, 6400-6411.

11 M. Suto, Y. Hirota, H. Mamiya, A. Fujita, R. Kasuya, K. Tohji and B. Jeyadevan, J. Magn. Magn. Mater., 2009, 321, 1493-1496.

12 A. Tomitaka, A. Hirukawa, T. Yamada, S. Morishita and Y. Takemura, J. Magn. Magn. Mater., 2009, 321, 1482-1484.

13 C. S. S. R. Kumar and F. Mohammad, Adv. Drug Delivery Rev., 2011, 63, 789-808.

14 T. Sadhukha, T. S. Wiedmann and J. Panyam, Biomaterials, 2014, 35, 7860-7869.

15 P. Pradhan, J. Giri, G. Samanta, H. D. Sarma, K. P. Mishra, J. Bellare, R. Banerjee and D. Bahadur, J. Biomed. Mater. Res., Part B, 2007, 81, 12-22, DOI: 10.1002/jbm.b.30630.

16 S. Mornet, S. Vasseur, F. Grasset and E. Duguet, J. Mater. Chem., 2004, 14, 2161-2175, DOI: 10.1039/B402025A.

17 S. Mornet, S. Vasseur, F. Grasset, P. Veverka, G. Goglio, A. Demourgues, J. Portier, E. Pollert and E. Duguet, Prog. Solid State Chem., 2006, 34, 237-247.

18 A. S. Teja and P. Koh, Prog. Cryst. Growth Charact. Mater., 2009, 55, 22-45.

19 I. Apostolova and J. M. Wesselinowa, Solid State Commun., 2009, 149, 986-990.

20 A. A. Kuznetsov, V. G. Leontiev, V. A. Brukvin, G. N. Vorozhtsov, B. Y. Kogan, O. A. Shlyakhtin, A. M. Yunin, O. I. Tsybin and O. A. Kuznetsov, J. Magn. Magn. Mater., 2007, 311, 197-203.

21 T. L. Kline, Y. Xu, Y. Jing and J. Wang, J. Magn. Magn. Mater., 2009, 321, 1525-1528.

22 M. Zeisberger, S. Dutz, R. Müller, R. Hergt, N. Matoussevitch and H. Bönnemann, J. Magn. Magn. Mater., 2007, 311, 224-227.

23 D. S. Nikam, S. V. Jadhav, V. M. Khot, M. R. Phadatare and S. H. Pawar, J. Magn. Magn. Mater., 2014, 349, 208-213. 
24 N. K. Prasad, L. Hardel, E. Duguet and D. Bahadur, J. Magn. Magn. Mater., 2009, 321, 1490-1492.

25 E. Pollert, P. Veverka, M. Veverka, O. Kaman, K. Záveta, S. Vasseur, R. Epherre, G. Goglio and E. Duguet, Prog. Solid State Chem., 2009, 37, 1-14.

26 S. Vasseur, E. Duguet, J. Portier, G. Goglio, S. Mornet, E. Hadová, K. Knížek, M. Maryško, P. Veverka and E. Pollert, J. Magn. Magn. Mater., 2006, 302, 315-320.

27 E. Pollert, K. Knížek, M. Maryško, P. Kašpar, S. Vasseur and E. Duguet, J. Magn. Magn. Mater., 2007, 316, 122-125.

28 O. Kaman, P. Veverka, Z. Jirák, M. Maryško, K. Knížek, M. Veverka, P. Kašpar, M. Burian, V. Šepelák and E. Pollert, J. Nanopart. Res., 2011, 13, 1237-1252.

29 N. D. Thorat, V. M. Khot, A. B. Salunkhe, R. S. Ningthoujam and S. H. Pawar, Colloids Surf., B, 2013, 104, 40-47.

30 N. D. Thorat, S. V. Otari, R. A. Bohara, H. M. Yadav, V. M. Khot, A. B. Salunkhe, M. R. Phadatare, A. I. Prasad, R. S. Ningthoujam and S. H. Pawar, Mater. Sci. Eng., C, 2014, 42, 637-646.

31 T. K. D. S. Das, J. Phys.: Condens. Matter, 2006, 18, 7629.

32 R. Epherre, C. Pepin, N. Penin, E. Duguet, S. Mornet, E. Pollert and G. Goglio, J. Mater. Chem., 2011, 21, 14990-14998.

33 G. D. V. A. Gaur, J. Phys.: Condens. Matter, 2006, 18, 8837.

34 P. Žvátora, M. Veverka, P. Veverka, K. Knížek, E. Pollert, V. Král, G. Goglio, E. Duguet, K. Záveta and O. Kaman, J. Solid State Chem., 2013, 204, 373-379.

35 E. Natividad, M. Castro, G. Goglio, I. Andreu, R. Epherre, E. Duguet and A. Mediano, Nanoscale, 2012, 4, 3954-3962, DOI: 10.1039/C2NR30667K.

36 C. Zener, Phys. Rev., 1951, 82, 403.

37 V. Markovich, A. Wisniewski and H. Szymczak, in Handbook of Magnetic Materials, ed. nonymous, Elsevier, 2014, vol. 22, pp. 1-201.

38 M. Abrashev, V. Ivanov, M. Iliev, R. Chakalov, R. Chakalova and C. Thomsen, Phys. Status Solidi B, 1999, 215, 631-636.
39 N. K. Prasad, K. Rathinasamy, D. Panda and D. Bahadur, J. Biomed. Mater. Res., Part B, 2008, 85, 409-416.

40 A. Urushibara, Y. Moritomo, T. Arima, A. Asamitsu, G. Kido and Y. Tokura, Phys. Rev. B: Condens. Matter Mater. Phys, 1995, 51, 14103-14109.

41 L. Nalbandian, A. Evdou and V. Zaspalis, Int. J. Hydrogen Energy, 2009, 34, 7162-7172.

42 M. P. Pechini, Method of preparing lead and alkaline earth titanates and niobates and coating method using the same to form a capacitor, US Pat., 3330697 A, 1967.

43 S. Liu, X. Tan, K. Li and R. Hughes, Ceram. Int., 2002, 28, 327-335.

44 C. H. Chen, H. Kruidhof, H. J. M. Bouwmeester and A. J. Burggraaf, Mater. Sci. Eng., B, 1996, 39, 129-132.

45 R. R. Wildeboer, P. Southern and Q. A. Pankhurst, J. Phys. D: Appl. Phys., 2014, 47, 495003.

46 S. Anisimov, B. Kapeliovich and T. Perelman, Zh. Eksp. Teor. Fiz., 1974, 66, 375-377.

47 A. Da Silva, L. D. Conceição, A. Rocco and M. Souza, Ceramica, 2012, 58, 521-528.

48 N. Zhang, W. Yang, W. Ding, D. Xing and Y. Du, Solid State Commun., 1999, 109, 537-542.

49 M. Dokiya, Proceedings of the Fourth International Symposium on Solid Oxide Fuel Cells (SOFC-IV), The Electrochemical Society, 1995.

50 D. Green and K. Neumann, arXiv preprint arXiv:1105.2700, 2011.

51 A. Mellergård, R. McGreevy and S. Eriksson, J. Phys.: Condens. Matter, 2000, 12, 4975.

52 A. Rostamnejadi, H. Salamati, P. Kameli and H. Ahmadvand, J. Magn. Magn. Mater., 2009, 321, 3126-3131.

53 Z. F. Zi, Y. P. Sun, X. B. Zhu, Z. R. Yang, J. M. Dai and W. H. Song, J. Magn. Magn. Mater., 2009, 321, 2378-2381.

54 R. T. Shannon, Acta Crystallogr., Sect. A: Cryst. Phys., Diffr., Theor. Gen. Crystallogr., 1976, 32, 751-767. 